\title{
Dentists seek action to improve school meals
}

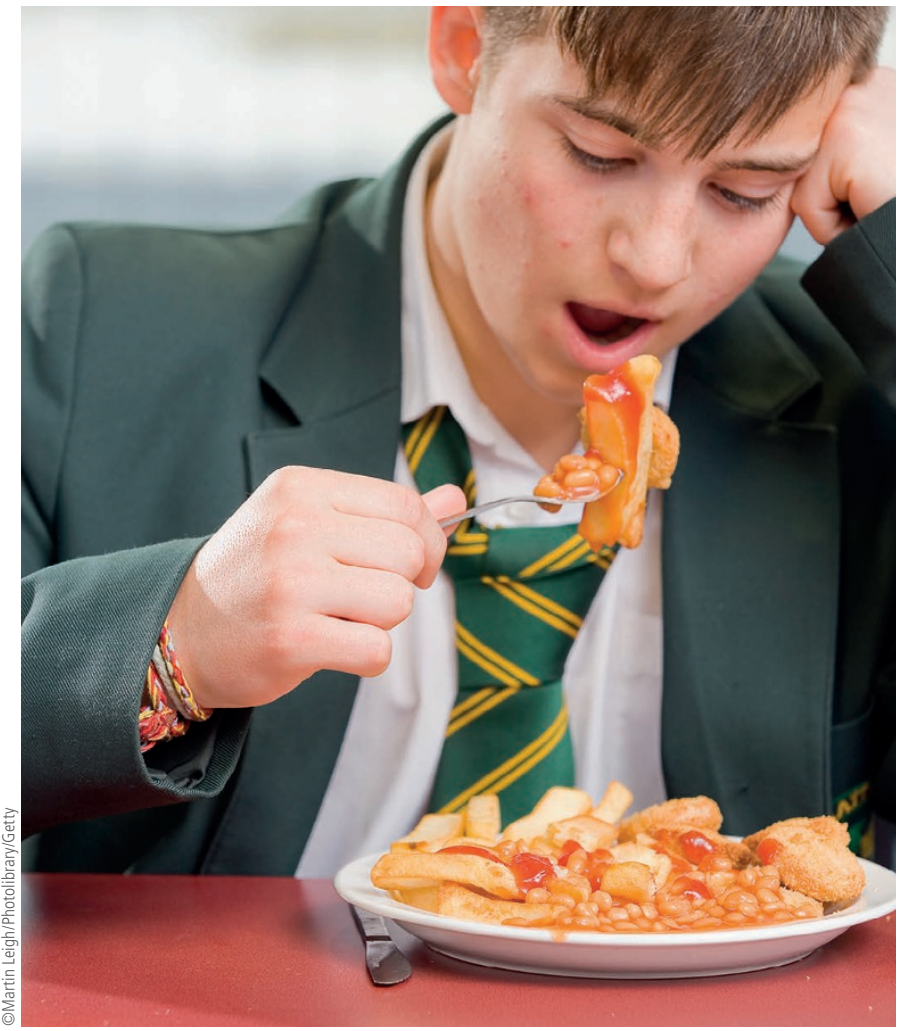

Dental leaders in Scotland have called for improvements to the lunchtime menu in Scottish schools to reduce excess sugar and ensure children and young people eat more fruit and vegetables.

The Faculty of Dental Surgery of the Royal College of Physicians and Surgeons of Glasgow has published its official response ${ }^{1}$ to the Scottish Government's national consultation ${ }^{2}$ on the nutritional requirements for food and drink in schools, which closed in August 2018.

In its submission, the Faculty, which represents more than a thousand dentists and trainees, called for schools to remove unhealthy puddings from their lunchtime menus, and proposed the alternative of offering pupils a healthier choice of soup or fruit.

The consultation proposed:

- Increasing access to fresh fruit and vegetables with a minimum of two portions of veg and a portion of fruit to be offered as part of a school lunch
- Introducing lower sugar limits in foods such as breakfast cereal and yoghurts

- Reducing how often sweetened and baked goods were available in primary schools

- No longer offering fruit juice and smoothies in primary and secondary schools

- Introducing a new regulation for red meat, specifying how much of a child's weekly intake should be high-quality produce and limiting the amount of processed meat.

Faculty Dean Professor Graham Ogden said: 'We fully support the positive intention of these proposed regulations, but we feel that the Scottish Government should take a bolder approach if it's to ensure that our young people have the healthiest possible start in life.

'For example, we all agree that children should have greater access to more fruit and vegetables as part of their school day, but increasing access does not necessarily increase consumption. The guidance must include an evidence based plan to ensure any increase in provision also ensures that our young people consume larger amounts of healthier food during school meals.

'In addition, our membership also welcome the intention to reduce the free sugar content of school meals. However, we totally oppose the inclusion of sugar-free drinks on the list of permitted drinks for secondary school as this could see the reintroduction of diet fizzy drinks.

'Some will argue sugar free is a harm reduction approach, but it has all of the well-known disadvantages of that tactic. We also know that diet drinks cause dental erosion, in addition to being a gateway to sugar.'

The Faculty's submission also called for steps to ensure all children and young people had access to facilities in schools to brush their teeth after meals.

'Around a third of Scottish children currently suffer from dental decay', added Ogden. 'This consultation process is a good start by the Scottish Government, but it doesn't go far enough if we're to effectively tackle this serious problem.'

1. Faculty of Dental Surgery of the Royal College of Physicians and Surgeons of Glasgow. Submission to the Scottish Government Consultation on Nutritional requirements for food and drink in schools: consultation' (21 September 2018). Available at https://rcpsg.ac.uk/ news/2632-dentists-call-for-positive-action-on-school-meals (accessed 24 September 2018).

2. Scottish Government. Nutritional requirements for food and drink in schools: consultation (4 June to 29 August 2018). Available at https://consult.gov.scot/support-and-wellbeing/ food-and-drink-in-schools/ (accessed 24 September 2018).

\section{BDA AGMs}

The Branch AGM for the Central Counties BDA Branch will take place on Wednesday, 7 November 2018 at the Harborne Golf Club, 40 Tennal Road, Birmingham, B32 2JE. The meeting begins at 19.00 .

The Branch AGM for the Eastern Counties BDA Branch is taking place on Wednesday, 7 November 2018 at the Ravenwood Hall, Bury St Edmunds, IP30 9JA. The meeting begins at 20:00.

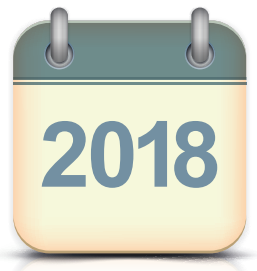

To book a place at either event or to offer your apologies, please contact Sarah Rockliff, Events and Branch Support Executive, at branchsectionevents@bda.org or visit www. bda.org/centralcountiesagm or https://www.bda.org/events/ branches-sections/eastern-counties-agm-wednesday-7-november-2018 to book places online. 